\title{
Effects of Farmers' Facial Expression on Consumers' Responses in Print Advertising of Local Food: The Moderating Role of Emotional Intelligence
}

\author{
Yumi Seo and Yeong Seon Kang \\ Department of Business Administration, University of Seoul, 163 Seoulsiripdae-ro, Dongdaemun-gu, Seoul 02504, \\ Republic of Korea \\ Correspondence should be addressed to Yeong Seon Kang; yskang2014@uos.ac.kr
}

Received 31 March 2020; Revised 24 August 2020; Accepted 7 September 2020; Published 15 September 2020

Academic Editor: Encarna Aguayo

Copyright (C) 2020 Yumi Seo and Yeong Seon Kang. This is an open access article distributed under the Creative Commons Attribution License, which permits unrestricted use, distribution, and reproduction in any medium, provided the original work is properly cited.

\begin{abstract}
In the context of ethical consumption, we examine the effects of farmers' facial expression in print advertising on consumers' responses to local food. Furthermore, we try to verify the moderating role of emotional intelligence (EI) on consumers' responses to the advertising message strategy. The advertising message strategy that connects farmers and consumers is expected to create more favorable responses among consumers toward local food and its retailers. This study examines consumers' responses (perceived product quality, trust, and a positive attitude toward the local food retailer) to three conditions of farmers' facial expression in the advertisement (neutral facial expression, positive facial expression, and product only, with no portrait) across two levels of EI (low and high). We find that farmers' positive facial expressions in the advertisements have the greatest positive effects on consumers' perceived product quality, trust, and attitude toward the local food retailer under a high level of EI. Therefore, individuals with a high level of EI were more influenced by facial expressions in print advertising, whereas those with a low level of EI were less influenced by facial expressions in print advertising, and their responses were indifferent to whether the local food farmer had a neutral or a positive facial expression in print advertising. Our findings suggest that marketing practitioners consider personal characteristics such as EI in persuading local food consumers in target markets to implement strategies to promote local food purchase and consumption.
\end{abstract}

\section{Introduction}

Ethical consumption can be defined as making conscious choices according to ethical value judgments or making what they feel are ethically correct choices when consumers buy goods or services $[1,2]$. Ethical consumers consider environmental and ethical aspects when selecting products and services [1]. Additionally, ethical consumers focus on social values to further improve their community [3]. Crane and Matten [4] noted that an ethical consumer makes a conscious and deliberate choice of consumption according to moral beliefs. Ethical consumers are expected to favorably appreciate products of social value that seek to develop social communities [5]. Ethical consumers expect that the product does not harm human beings, animals, or the environment.
Sometimes, it comprises a portion of the sales figure donated to an environmental or charity group. Ethical consumption exemplifies various activities in four dimensions: human activity and social responsibility (fair trade, local purchasing, labor rights, consumption resection, and social contribution), legal responsibility (protection of copyright and actions of social enterprises), animal welfare activities, and environment (activities that are considered environmentally friendly) $[6,7]$.

Ethical consumption has become a new trend in South Korea. One Korean market research company, Embrain, announced the results of a survey conducted in July 2017 on 2,000 men and women aged between 19 and 59 years [8]. According to the report, about $60 \%$ of respondents said they had been ethical consumers during the previous year, and 
even if the ethical products were more expensive, their intention to purchase ethical products was over $70 \%$. In particular, ethical consumption is actively increasing in everyday food consumption. With globalization and the increasing import and export of food, the stability and safety of ingredients have become a problem. The importation of foreign agricultural products is increasing concerns about chemical treatment and environmental pollution. Doubts about food safety have prompted consumers to start demanding information and transparency about food production sources [9]. Many consumers are more aware of food freshness and safety than they were in the past. Consequently, interest in local food consumption is increasing, with expanding related market channels. Research on local food consumption has been increasing rapidly in consumer behavior and in social responsibility research [10].

"Local food" has a short travel distance from production to sale, or the producers sell it directly [11]. Generally, local food is defined as food produced in the region and supplied directly by producers through the streamlining of the distribution process, ensuring a fair price [11]. Local food consumption helps the sale of local commodities in the region, revitalizes the local economy, and addresses health and impact issues, such as drug disposal and freshness degradation from remote travel. In addition, local food consumption creates social benefits in terms of lower energy usage and lowers greenhouse gases caused by $\mathrm{CO}_{2}$ emissions from remote transportation. On the supply side, producers can expect income from stable demand because sustainable agriculture has the advantage of activating the local economy. On the demand side, unlike organic food, buying local food is not perceived as expensive [9]. Additionally, local food is not only a good alternative, to imported food environmentally and economically, but is also perceived as fresh, healthy, and safe. In summary, the reasons for local food consumption are not only product quality and sustainability but also its actual benefits (fresh, healthy, and easy to use) [12].

In this study, we focus on local food advertisements and attempt to find a way to communicate effectively with consumers to revitalize the local food market. In particular, we examine the impact of producers' characteristics on consumer reactions, as depicted in advertising messages that encourage positive responses to local food advertisements. In this case, we will use locally grown fruits as the experiment's stimulus, with local food farmers encouraging consumption through advertisements that promote domestic vegetables and fruits with local production information. In a study of donation behavior, Kogut and Ritov [13] showed that donors engage with potential beneficiaries more deeply, and their donation intention increases when they can see the faces of potential beneficiaries in photographs. We expect these research results on donations to be equally viable from the perspectives of a producer and consumer in the context of ethical consumption.

It is important to examine the impact on consumers' perception and attitude of a local food advertising strategy that appeals to social values. We empirically examine whether consumers' responses to local food advertisements can be formed by showing photos of the producers, depending on consumers' EI. The role of EI in the ethical decisions of managers and employees in companies and organizations has emerged in organizational behavioral research [14]. Recently, the impact of EI on the ethical decision-making process has been examined in psychology and behavior research $[15,16]$. Robinson et al. [15] showed that EI has a positive effect on environmentalism among adolescents using a survey. They explained that consumers with high EI can predict that their environmental concerns will ultimately have a positive impact on the environment, and that they can be more active in environmental protection behavior [16]. Consumers' personal characteristics, such as EI, should be an important criterion for evaluating and choosing ethical products. This study aims to present consumers' EI as a moderating factor causing their differentiated responses to producers' facial expressions. The purpose of this study is to investigate the effect of consumers' responses when they see a producer's face in the local food advertisement. Finally, we propose an effective advertising message strategy for companies that want to promote local food purchase and consumption.

\section{Conceptual Framework and Hypotheses}

2.1. Image and Facial Expressions of Local Food Farmers. Ethical consumption is a conscious consumption choice based on personal and moral beliefs, and consumers consider their own well-being and that of society and the environment at the time of purchase and consumption. Local food consumption helps to revitalize the local economy [17]. Consumers concerned with global climate change and environmental issues tend to actively purchase organic and local foods [18]. In local food supply systems, direct transactions between producers and consumers reduce transportation and packaging costs. According to consumer studies in the United States, the important factors that affect the consumption of local food are "quality" and "local economy support" [19]. Local food consumers generally have a significant interest in local economic support [20]. In addition, they are aware of the relationship between the local economy and local food consumption. The local food supply system supports small- and medium-sized family farms so that not only large-scale commercial farms but also smalland medium-sized family farms can continue farming in the community.

South Korea has achieved economic development centered on manufacturing and industrial areas, while agriculture has become relatively alienated (Korea Customs and Trade Development Institution) [21]. In addition, the food distribution structure is complex, and profit to producers is relatively small. Therefore, consumers are aware of the threat to the agricultural community. Local food promotes domestic food production and maintains food sovereignty. Local food consumers experience a partnership through sympathy with the producer and communal sympathy through local food consumption. From the perspective of distribution companies, product differentiation using local food can strengthen product competitiveness, and 
distribution companies can promote local food and grow with producers by linking producers and consumers of local food.

Local food is also important in terms of purchasing safe and reliable food that is directly linked to health [17]. With industrialization and globalization, food is circulated internationally, and consumers find it difficult to understand who produces the food they eat and how they do so. Complications in the distribution stages can lower food quality and reliability. As the distrust in food safety grows, interest in local food consumption increases. Today, consumers want to identify producers who can ensure safe consumption of food and reliable distributors who can ensure its supply. Consumers often have positive feelings about how food is produced, and knowing this has a positive impact on their trust level and perception of product quality. Local food is distributed from geographically close areas to increase consumers' trust in the producer and the food. In addition, this is seasonal food produced just before it is sold, and it is not stored for a long time after being mass-produced and distributed. Therefore, local food can be recognized as fresh and safe, with high quality.

Because it is difficult for the human brain to process a large amount of information simultaneously, it is necessary to make a judgment only with some cues. Research in psychology and neuroscience has revealed that humans instinctively see faces more intensively than other objects [22]. Droulers and Adil [23] compared print advertisements with and without face images and found that face images had a positive effect on memorizing and recalling advertisements. The face contains various types of information, including physical information such as not only race, age, and gender but also the emotional state of the person. Bakhshi et al. [24] found that posts with face images on social media received more attention and likes than those without face images. Guido et al. [25] examined consumers' responses to print advertising with and without face images and found that the presence of face images attracts more attention from consumers. In particular, this effect was significantly maintained not only for a real face image but also for a pareidolia image with the shape of a human face.

Presenting the face of the food producer as information in the advertisement can be applied using the dual processing model (elaboration likelihood model (ELM)) [26] in consumer behavior. According to the ELM, persuasion to change attitude can be achieved through the central processing route and the peripheral processing route [26]. The central processing route tackles the contents of the information directly related to the subject, and it induces careful attention and effort. The central processing route requires cognitive abilities and the cognitive effort of information processors by consumers [27]. The peripheral processing route affects decision-making through indirect cues that are not directly related to the subject. In an advertisement, the use of extrinsic visuals such as advertising models rather than products can be an example of indirect cues.

Emotional contagion theory explains whether one's emotions cause similar emotions or behaviors to others $[28,29]$. In other words, the emotions from a person's facial expressions can affect the emotions and behaviors of others. People unconsciously or consciously imitate emotions from facial expressions in the process of interacting with others [30]. Based on the emotional contagion theory, Isabella and Viera [31] showed that observers exposed to smiling face images in print advertisements feel positive. Emotional incentives from positive facial expressions influence consumers' evaluation of the product in the decision-making process.

Plutchik [32] found that emotions such as sadness, anger, joy, and pain appear through different facial expressions, and it was possible to detect the emotions of the other party by looking at their facial expressions. Consumers can sense emotions through the facial expressions of the people appearing in the advertisement. Facial expressions in the ad are prominent clues that draw consumers' attention and consumers first look at the model's facial expressions when viewing the advertisement [33]. Howard and Gengler [34] examined the effects of sellers' facial expressions on product evaluation and found that a positive facial expression is more positively evaluated than a negative facial expression.

To evaluate the physical attractiveness, perceived trust, and expertise of the advertising model, consumers will be reminded of memories formed through direct or indirect experiences, and advertising will be directed to recall memories [35-37]. Advertising can cause emotional empathy through facial expressions. Providing specific information of an individual can enhance empathy, and attitudes can be positive when empathy is high.

Research on the facial expressions of the advertising model in areas of ethical consumption has been extensively addressed with regard to donation behavior [38]. Fundraising appeals by organizations attract donations by drawing attention to the advertisements instantaneously in a personal, emotional experience, when consumers see the donation beneficiary's facial expressions in the ad. A donor looking at children with sad faces, who are suffering from starvation, or are refugees, will want to escape the negative situation by feeling empathy. However, looking at a child with a happy expression will bring the donor self-esteem. If the model in the advertisement has a sad facial expression, the audience of the advertisement is more sympathetic to the model, and because they feel sadness and anxiety about the model, the donation intention is more positive than for a model with a happy facial expression. In general, it is known that appealing to negative emotions rather than positive ones causes a stronger consumer response. Slovic [39] found that, in a donation behavior study, the more specific the information about the beneficiaries, the greater the emotional response triggered. If the model appearing in the ad is not a celebrity and is unknown, the evaluation of the advertisement will be focused on the features appearing on the addirected surface, such as clothes, facial expressions, and gaze [35]. Using a neuromarketing method, Lee et al. [40] found that when seeing the faces of potential beneficiaries of fairtrade products, the degree of activation of the brain changed. In their experiment, face-to-face contact showed more brain activation than did control conditions. In other words, 
consumers will be more responsive to advertisements with the food producer as an advertising model rather than advertisements with the products alone. Based on these discussions, we derive the following hypotheses:

Hypothesis 1. (H1). Farmers' positive facial expressions in the print advertising of local food have the greatest effects on consumers' responses.

H1 (a). Consumers perceive product quality to be higher when exposed to a farmer's positive facial expressions in the print advertising of local food than when exposed to neutral facial expressions.

H1 (b). Consumers perceive higher trust when exposed to a farmer's positive facial expressions in the print advertising of local food than when exposed to neutral facial expressions.

H1 (c). Consumers have more favorable attitudes toward local food retailers when exposed to a farmer's positive facial expressions in the print advertising of local food than when exposed to neutral facial expressions.

2.2. Moderating Role of Emotional Intelligence. According to Salovey and Mayer [41], who originally proposed the category of emotional intelligence, EI is "a set of skills hypothesized to contribute to the accurate appraisal and expression of emotion in oneself and in others, the effective regulation of emotion in self and others, and the use of feelings to motivate, plan, and achieve in one's life." Many researchers who discuss EI fall into four dimensions: emotion recognition, understanding, control, and utilization [42]. Based on this four-dimensional model of EI, Wong and Law [43] developed a scale to measure EI. The first dimension of EI is self-emotion appraisal (SEA), that is, the recognition, evaluation, and expressiveness of one's emotions. The second dimension of EI is others' emotion appraisal (OEA), which indicates the ability to recognize and understand other people's emotions. The third dimension is regulation of emotion ( $\mathrm{ROE}$ ), and it is associated with an individual's ability to modulate emotions to quickly recover from psychological distress. The last dimension is the use of emotion (UOE), that is, the ability to utilize one's feelings to focus on constructive activities and achievement of individual performance. The $\mathrm{UOE}$ is the ability to motivate and achieve personal and professional success. Therefore, it is not an ethical aspect, but it is closely related to a productive and administrative aspect [42]. Huang et al. [44] found that the UOE has a positive relationship with work performance and reported that ethical behavior and UOE are not related. Joseph et al. [45] and Fu [46] also showed that the UOE is not related to ethical behavior perceptions. Thus, Chowdhury [47] excluded UOE in his research on the relationship between consumer ethics and EI. Based on these results, we would like to conceptually define and use EI in three dimensions-SEA, OEA, and ROE-excluding the fourth dimension, UOE.
The higher the EI to recognize and manage one's emotional state and of others, the higher the empathy in understanding an opponent's feelings, beyond the difference in the social environment [48]. The research results have consistently linked higher EI to more empathic behavior [49-51].

Consumers are able to identify producers when viewing a farmer's face in the local food ads. If consumers identify with the producers, it is likely that they will have empathic reactions. Empathy has been studied as an important theoretical variable in ethical consumption activities with the ability to understand the situations and emotions of others [52]. Thus, if the producer's information is concrete, it is expected that consumers with high EI levels will show stronger reactions. Individuals with high levels of EI will be more dependent on the facial expression of the model in the advertisement. In other words, individuals with high levels of EI will respond more strongly to an advertisement in which local food producers appear than will individuals with low levels of EI. When individuals with high levels of EI are exposed to a positive facial expression by the local food producer, a more favorable response is expected. However, when individuals with high EI levels are exposed to a neutral facial expression of the local food producer, they will have negative responses because they can recognize and understand the emotions of others. Individuals with low levels of EI will be less influenced by the facial expression of the advertising model in the advertisement. Therefore, when individuals have low levels of EI, they may respond indifferently to neutral and positive facial expressions of local food producers. Based on these discussions, we derive the following hypotheses:

Hypothesis 2. (H2). The relationship between the local food producer's facial expression in the advertisement and consumers' responses will be moderated by emotional intelligence. Specifically, individuals with high levels of EI will respond more strongly after seeing the producer's facial expression, whereas individuals with low levels of EI will respond indifferently under any condition.

2.3. Research Method. In the context of local food advertisements, we use a scenario-based between-subjects experiment design to compare two facial expressions by the same producer, a farmer, in our case: neutral and positive faces. In addition, to compare the conditions of facial expression, our third level of experimental treatment is a control condition without the farmer's face image and showing only the product itself. A total of 160 undergraduate students from a university located in Seoul, South Korea, participated in the experiment. The participants were granted extra credit as a token of appreciation.

We randomly assigned participants to one of three conditions (neutral facial expression, positive facial expression, and a product image only, without any portrait). Participants' ages ranged from 18 to 32 years, with a mean age of 22 years, and $54 \%$ of the participants were male and $46 \%$ were female. After the participants read a simple 
scenario, we asked them to answer questions to measure their trust, their attitude toward the local food retailer, and their perception of product quality, to measure their EI and product involvement and to examine the manipulation of facial expression.

We used a leaflet as a stimulus to provide information about its producer and the product in our study. We created a fictitious retail store (XYZ local food store, which sells domestically grown fruits and vegetables) for the experiment to control preexisting knowledge and attitudes. We manipulated the leaflet content to reflect the three conditions of product and producer information. Our advertising leaflet contained stimuli portraying a neutral facial expression, a positive facial expression, or a photo of the product alone, without any portrait. To prevent potential confounding effects, all experimental leaflet contents used the same format and structure.

Among the many types of local food, we chose Koreangrown melon in the fruit and vegetable category, for our experiments. In South Korea, fruit imports are increasing every year; in 2017, South Korea imported 860,000 tons of fruits. Consumer preferences have diversified, and demand for tropical fruits has increased in general. The main imported fruits in South Korea are kiwis, melons, pineapples, and mangos. Various fruits are imported in some countries through the Free Trade Agreement (FTA) [53], and the prices of imported fruits are low, while the demand for imported fruits is high. Recently, however, the domestic melon has been increasingly circulating in domestic consumer markets with higher sugar content and more varieties. Consequently, both the cultivated area and the amount produced have increased, and domestic melons can be easily brought into the market (Korea Customs and Trade Development Institution) [17].

Positive emotions can be mostly expressed by a smile and a laugh; when these occur, the cheekbones of the face go up slightly and the facial muscles pull up. In some cases, the cheeks rise and the gap between the eyes becomes slightly narrower. Occasionally, wrinkles appear on the outside of the eyes [54]. We collected photographs of farmers (local food producers) on the Internet that match neutral and positive emotions. As familiarity may affect the effectiveness of advertisements already seen, we collected the photographs from publicly available photographs for reuse rather than from actual advertisements. To control for the preference of one model over another, we selected photographs in which the same person appeared. Figure 1, shows the stimuli used in our experiment.

Before viewing the leaflet, all subjects read the same description: "Imagine the following. One day, you see the following advertisement. The leaflet displays news about a specialty store, XYZ food store, that sells fruits and vegetables produced in the countryside near your house." The subjects then viewed a leaflet that was randomly assigned to them, demonstrating one of three conditions: a neutral facial expression, a positive facial expression, or a product alone. After the participants read the simple scenario, we asked them to evaluate the XYZ local food store and answer questions about their interest.
Measures from the literature provided the basis for our dependent measures. Perceived product quality is defined as consumers' judgment of the quality of local food provided by the local retailer [55]. We used three items on a seven-point Likert scale $(1=$ "strongly disagree" to 7 being "strongly agree;" Cronbach's alpha $=0.807)$ to measure perceived product quality: (1) "The quality of fruits provided by the XYZ local food store is high;" (2) "The quality of fruits provided by the XYZ local food store is consistently high;" and (3) "The quality of fruits provided by the XYZ local food store will be superior to others." We used three items from Ganesan and Hess [56] on a seven-point Likert scales (1 being "strongly disagree" to 7 being "strongly agree;" Cronbach's alpha $=0.957)$ to measure trust toward the local food retailer: (1) "I can believe in the XYZ local food store;" (2) "I trust the XYZ local food store;" and (3) "Buying at the $\mathrm{XYZ}$ local food store is reliable." A four-item semantic differential scale from Homer [57] (bad/good; not favorable/ favorable; negative/positive; and likeable/not likable) measured attitudes toward the local food retailer (Cronbach's alpha $=0.923$ ).

Last, we asked them to measure their EI using the Wong and Law Emotional Intelligence Scale (WLEIS) [43]. The WLEIS consists of 16 items for four dimensions of EI: SEA, OEA, ROE, and UOE. For reasons discussed earlier, we did not include UOE in any of the analyses. Each item consisted of a seven-point Likert scale ( 1 = "strongly disagree" to 7 being "strongly agree"), and EI was evaluated by the average value obtained by adding up the measurements of these three dimensions of EI: SEA (Cronbach's alpha $=0.871$ ), OEA (Cronbach's alpha $=0.874$ ), and ROE (Cronbach's alpha $=0.898)$. We conducted a factor analysis to assess the construct validity of the measures of EI. The following table shows the results of the principal component analysis (using varimax rotation). Using the criterion of an eigenvalue greater than one, the validity between the constructs was confirmed. Table 1 shows the results of the factor analysis.

We measured EI using the questionnaire items as a variable of an interval scale, then classified it into two groups based on the median value (median $=4.917$ ), and tested the hypothesis as a variable of a nominal scale. Table 2 shows the average, standard deviation, and sample numbers of the groups based on the level of EI.

As a control variable, we measured involvement. Involvement is commonly defined as a consumer's enduring perceptions of a product's importance based on that consumer's inherent needs, values, and interests [58]. We used involvement as a covariate in our analyses to control its effect on the dependent variable. A three-item semantic differential scale from Zaichkowsky [59] (unimportant/important; not interested/interested; and unrelated/related) measured involvement (Cronbach's alpha $=0.943)$.

\section{Results}

3.1. Manipulation Checks. We conducted a manipulation check to verify the perception of the producer's facial expression. Respondents answered the question: "It seems that the person in the picture is smiling" on two 7-point Likert 


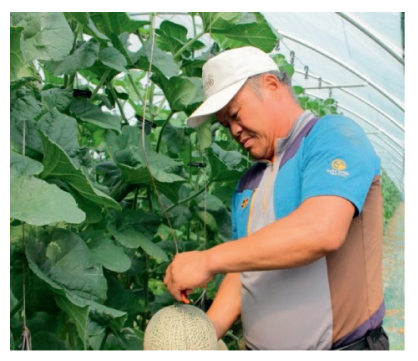

(a)

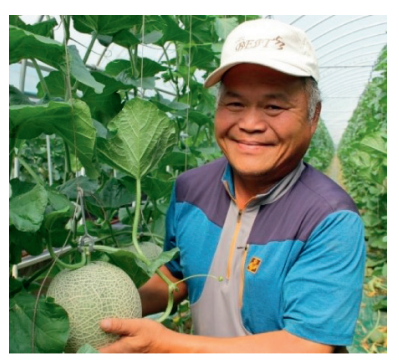

(b)

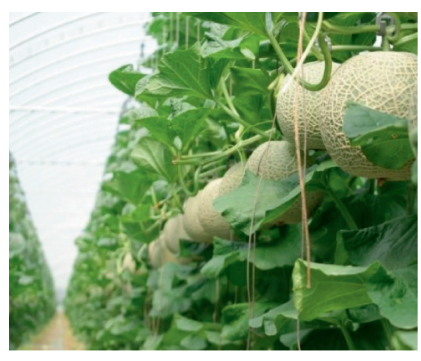

(c)

Figure 1: Farmer's facial expression in print advertising, (a) neutral facial expression, (b) positive facial expression, and (c) product without portrait.

TABLE 1: Measurements of EI and factor analysis results.

\begin{tabular}{|c|c|c|c|}
\hline Items & SEA & OEA & ROE \\
\hline (1) I have a good sense of why I have certain feelings most of the time. & 0.824 & 0.146 & 0.129 \\
\hline (2) I have good understanding of my own emotions. & 0.886 & 0.163 & -0.002 \\
\hline (3) I really understand what I feel. & 0.885 & 0.193 & 0.056 \\
\hline (4) I always know whether I am happy or not. & 0.738 & 0.110 & 0.078 \\
\hline (5) I always know my friends' emotions from their behavior. & 0.242 & 0.870 & 0.121 \\
\hline (6) I am a good observer of others' emotions. & 0.002 & 0.842 & -0.129 \\
\hline (7) I am sensitive to the feelings and emotions of others. & 0.242 & 0.873 & 0.069 \\
\hline (8) I have a good understanding of the emotions of people around me. & 0.195 & 0.745 & 0.236 \\
\hline (9) I am able to control my temper so that I can handle difficulties rationally. & 0.201 & 0.133 & 0.798 \\
\hline (10) I am quite capable of controlling my own emotions. & 0.091 & 0.041 & 0.910 \\
\hline (11) I can always calm down quickly when I am very angry. & -0.023 & -0.016 & 0.855 \\
\hline (12) I have good control of my own emotions. & 0.019 & 0.095 & 0.924 \\
\hline Eigenvalue & 2.761 & 1.832 & 4.479 \\
\hline Percentage of variance (\%) & 23.008 & 15.270 & 37.325 \\
\hline
\end{tabular}

TABLe 2: Two groups by level of EI.

\begin{tabular}{lccc}
\hline Group & $N$ & Mean of EI & S.D. of EI \\
\hline Low EI & 79 & 4.279 & 0.472 \\
High EI & 81 & 5.519 & 0.408 \\
Total & 160 & 4.906 & 0.762 \\
\hline
\end{tabular}

scales (1-strongly disagree and 7-strongly agree). The independent $t$-test results indicated that the two conditions of facial expression were significantly different from each other. As per expectations, consumers were in higher agreement that the facial expression of the producer was positive than they agreed about whether the producer had a neutral facial expression $\left(M_{\text {positive }}=4.580\right.$ vs. $M_{\text {neutral }}=4.095 ; t=9.210$, $p<0.001)$. Thus, the two conditions of facial expression were successfully manipulated.

3.2. Hypothesis Testing. We tested the two research hypotheses using analysis of covariance (ANCOVA) to determine the existence of significant interaction effects between the farmers' facial expression in print advertising as a model and level of EI on consumers' responses (perceived product quality, trust, and attitude toward the local food retailer), while controlling for the effect of involvement (Table 3).
We found the main effect of the farmers' facial expression on consumers' perceived product quality ( $F(2$, $159)=3.323, p=0.039)$, trust $(F(2,159)=6.604, p=0.002)$, and their attitude toward the local food retailer $(F(2,159)=$ 2.367, $p=0.097$ ). We conducted follow-up tests in which we split the data according to their level of EI and conducted one-way ANCOVA tests, controlling involvement as a covariate.

Under the condition of low levels of EI, we found no significant effects of the farmers' facial expression in the advertisement on the consumers' perception of product quality and their attitudes toward the local food retailer. Respondents did not substantially distinguish the farmers' facial expression in local food advertising when the respondents had low EI levels.

With high EI levels, we found significant effects of the farmers' facial expression in the advertisement on perceived product quality $(F(2,80)=4.495, p=0.014)$, trust $(F(2$, $80)=5.271, p=0.007)$, and attitudes toward the local food retailer $(F(2,80)=7.055, p=0.002)$. When the respondents had a high level of EI, they showed significantly higher perceived product quality, trust, and attitude toward the local food retailer when they saw a positive facial expression on the local food farmer in the advertisement. When the respondents had high levels of EI, they showed a significantly unfavorable attitude toward the local food retailer when they saw a neutral facial expression on the local food farmer in the 
TABLE 3: Analysis of covariance (ANCOVA) results.

\begin{tabular}{|c|c|c|c|c|}
\hline & Involvement (covariate) & Farmers' facial expression & Level of EI & Interaction \\
\hline Perceived product quality & $\begin{array}{c}51.528^{* * *} \\
(0.000)\end{array}$ & $\begin{array}{l}3.323^{* *} \\
(0.039)\end{array}$ & $\begin{array}{c}0.440 \\
(0.508)\end{array}$ & $\begin{array}{l}2.365^{*} \\
(0.097)\end{array}$ \\
\hline Trust & $\begin{array}{c}57.644^{* * *} \\
(0.000)\end{array}$ & $\begin{array}{l}6.604^{* *} \\
(0.002)\end{array}$ & $\begin{array}{l}0.860 \\
0.355 \\
\end{array}$ & $\begin{array}{l}2.684^{*} \\
(0.072) \\
\end{array}$ \\
\hline Attitude toward the retailer & $\begin{array}{c}59.111^{* * *} \\
(0.000)\end{array}$ & $\begin{array}{l}2.367^{*} \\
(0.097)\end{array}$ & $\begin{array}{c}0.179 \\
(0.673)\end{array}$ & $\begin{array}{l}3.591^{* *} \\
(0.030)\end{array}$ \\
\hline
\end{tabular}

Note. $p$ values in parentheses. Farmers' facial expression (neutral vs. positive vs. product only, without portrait), level of EI (low vs. high). ${ }^{* * *} p<0.001$, ${ }^{* *} p<0.05$, and ${ }^{*} p<0.01$.

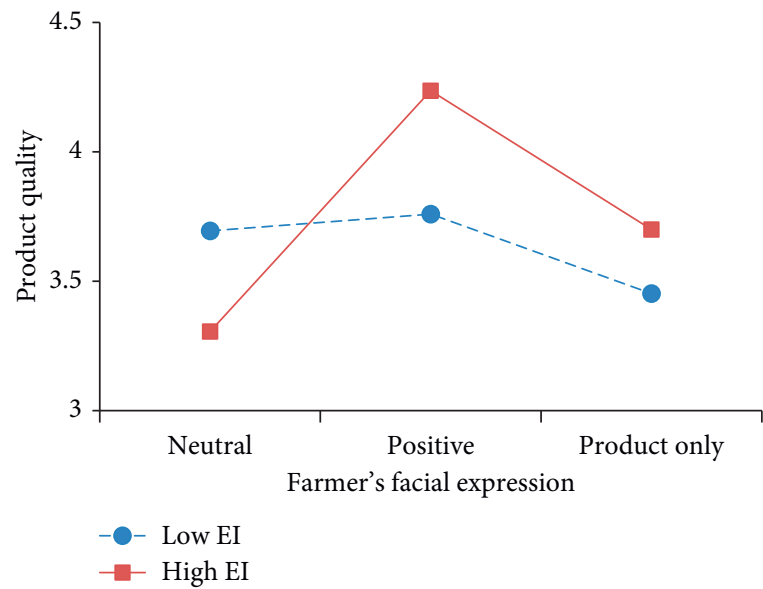

(a)

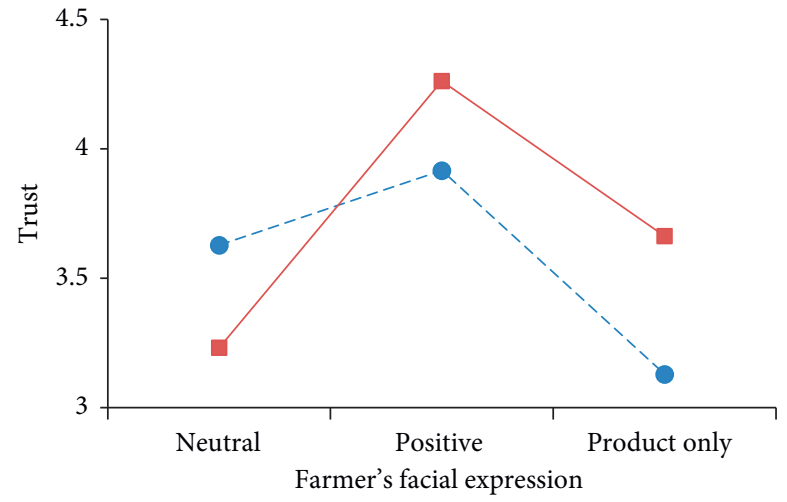

(b)

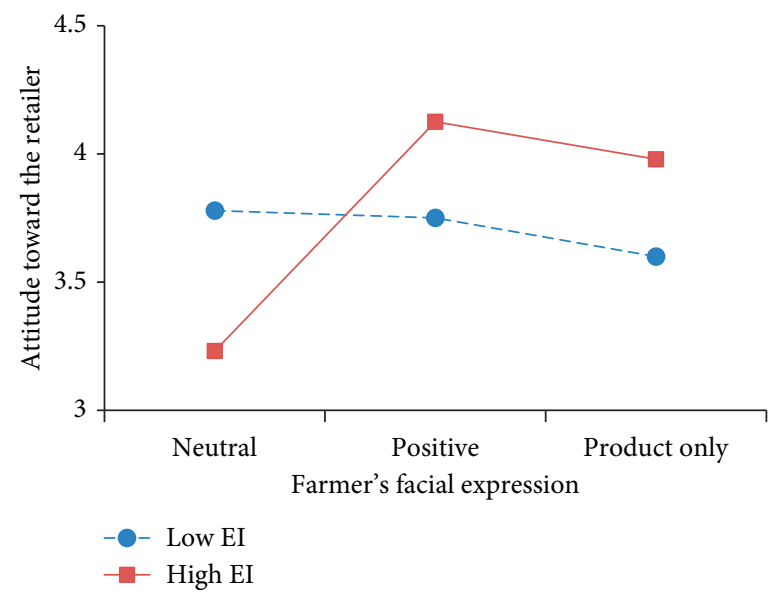

(c)

Figure 2: Interaction effect between farmers' facial expression (neutral vs. positive vs. product only, without portrait) and level of EI (low vs. high) in consumers' responses, (a) perceived product quality, (b) trust toward the local food retailer, and (c) attitude toward the local food retailer.

ad. Thus, Hypotheses H1, H1 (a), H1 (b), and H1 (c) were partially supported. These results are consistent with the literature on emotional contagion theory $[28,29,31,34]$.

A two-way ANCOVA test revealed a significant interaction effect between the farmers' facial expression and the level of EI on consumers' perceived product quality ( $F(2$, $159)=2.365, p=0.097)$. We performed follow-up tests to determine the effects on consumers' perceived product quality more closely. As Figure 2(a) shows, we could not find a significant simple effect of EI levels on consumers' perceived product quality under any condition. When respondents saw a neutral facial expression of farmers of locally grown fruits, they did not have different perceptions of product quality, regardless of whether they had low or 
high levels of EI $\left(M_{\text {low }}=3.695\right.$ vs. $M_{\text {high }}=3.306$; n.s. $)$. When a local store displays a positive facial expression of a farmer of locally grown fruits, the respondents do not have different perceived product quality, regardless of their level of EI $\left(M_{\text {low }}=3.760\right.$ vs. $M_{\text {high }}=4.236$; n.s. $)$. Similarly, when a local store provides information about the product without any portrait, the respondents do not have different perceived product quality, regardless of their level of EI $\left(M_{\text {low }}=3.453\right.$ vs. $M_{\text {high }}=3.700$; n.s.).

A two-way ANCOVA test revealed a significant interaction effect between the farmers' facial expression and the EI level on trust toward the local food retailer $(F(2,159)=$ 2.684, $p=0.072$ ). We performed follow-up tests to determine the effects on trust more precisely. As Figure 2(b) shows, we found a significant simple effect of the EI level on trust toward the local food retailer, for product information with a portrait, and insignificant simple effects for neutral and positive facial expressions. When a local store provides information on the product only, without a portrait, respondents who have high levels of EI show higher trust toward the local food retailer than do those with low levels of EI $\quad\left(M_{\text {low }}=3.129\right.$ vs. $M_{\text {high }}=3.663 ; F(2,158)=3.187$, $p=0.076)$. When respondents viewed neutral facial expressions from a producer of locally grown fruits, they did not show different levels of trust toward the local food retailer, regardless of their EI level $\left(M_{\text {low }}=3.628\right.$ vs. $M_{\text {high }}=3.232$; n.s.). Similarly, when the advertisement shows a positive facial expression of the producer, respondents' trust does not substantially distinguish between low and high levels of EI ( $M_{\text {low }}=3.916$ vs. $M_{\text {high }}=4.262$; n.s. $)$.

Finally, a two-way ANCOVA test revealed a significant interaction effect between the farmers' facial expression and the level of EI on consumers' attitude toward the local food retailer $(F(2,159)=3.591, p=0.030)$. We performed followup tests to determine the effects on consumers' attitudes more closely. As Figure 2(c) shows, we found a significant simple effect of the level of EI on consumers' attitudes toward neutral facial expressions and insignificant simple effects for positive facial expressions and for product information only with no portrait. When viewing the neutral facial expression of a producer of locally grown fruits, respondents with relatively high levels of EI show a less favorable attitude toward the local food retailer than do those who have relatively low levels of EI $\left(M_{\mathrm{low}}=3.779\right.$ vs. $\left.M_{\text {high }}=3.232 ; F(2,158)=3.812, p=0.053\right)$. When a local store provides a positive facial expression of the producer of locally grown fruits, respondents do not have different attitudes, regardless of their level of EI $\left(M_{\text {low }}=3.751\right.$ vs. $M_{\text {high }}=4.125$; n.s.). Similarly, when a local store provides information on the product only, without a portrait, respondents do not have different attitudes, regardless of their EI level $\left(M_{\text {low }}=3.600\right.$ vs. $M_{\text {high }}=3.979 ;$ n.s. $)$. Individuals with a high level of EI were more swayed by the facial expression of the model in the advertisement, and they responded more strongly to the advertisement in which local food producers appeared than individuals with low levels of EI. When individuals with high levels of EI were exposed to a positive facial expression of the local food producer, they perceived higher product quality and trustworthiness and had a more positive attitude toward the local food retailer. However, when individuals with high levels of EI were exposed to a neutral facial expression of the local food producer, they perceived lower product quality and trustworthiness and had a more negative attitude toward the local food retailer. Individuals with low levels of EI were less influenced by the facial expression of the model in the advertisement, and their responses were not significantly different between neutral and positive facial expressions of local food producers. Thus, Hypothesis H2 was supported.

\section{Conclusions}

In this study, we compared the presentation of the facial expressions of local farmers when publishing a producer's photo in print advertising. In particular, we compared neutral and positive facial expressions. Local food retailers seek to provide consumers with safe and healthy food at a fair price. Through local food retailers, producers maintain a reliable sales channel based on income growth and trust relationships with consumers. Local food brings economic benefits to both consumers and producers. From the perspective of society and community, economic revitalization and environmental pollution minimization can be achieved by local food consumption. This study aimed to examine an effective advertising message strategy for promoting local food purchases.

4.1. Theoretical Implications. We conducted a scenariobased experiment, and our findings have several implications for academic researchers in the areas of ethical consumption and the food industry. First, this study focuses on consumers' EI in ethical consumption, which is relatively unremarkable. In particular, we tried to investigate the relationship between ethical consumption and EI, which is a personal tendency variable. EI can be the ability of an individual to process information related to emotion. Next, our work shows that people with high levels of EI focus more on the producer's facial expression in the local food advertisement when the producer is appearing in the ads as an advertising model. Individuals with a high level of EI were more swayed by the facial expression of the advertising model in the advertisement, and they responded more strongly to the advertisement than individuals with a low level of EI. Respondents with high levels of EI showed significantly greater perceived product quality, trust and positive attitude toward the local food retailer after seeing a positive facial expression of the local food producer in the advertisement. Respondents with high levels of EI show a significantly unfavorable attitude toward the local food retailer when they see a neutral facial expression of the local food producer in the advertisement. Respondents with a low level of EI did not substantially distinguish between the presentation of the producer's information of local food advertising. Individuals with high levels of EI responded favorably to those favorable to them; however, if others were not favorable, they were rather cynical. In other words, they can control their reactions according to the reactions of 
others [60]. Viewing the producer's face was a strong stimulus for people with high levels of EI, and the effect was positive if it was a positive expression and negative if it was a neutral expression. The group with a high level of EI responded more sensitively to others' positive emotions. Thus, EI, which is sensitive to emotions, affects the response to advertising messages. Therefore, we sought to determine the moderating role of EI on advertising persuasion in local food advertisements. Our findings are consistent with the literature on emotion contagion theory $[28,29]$, and we demonstrated that the level of EI influences the degree of emotional contagion through print advertising with the farmers' facial expression to enhance the consumers' responses to local food.

4.2. Managerial Implications. Our findings suggest that marketing practitioners consider personal characteristics such as EI in persuading local food consumers in target markets to implement strategies to promote local food purchases. Making the producer's positive activities more appealing to the group with a high level of EI will be a more effective advertising message strategy in the local food market. The producer's facial expression imparts a sense of familiarity through the indirect experience of food. This increases consumers' perceived product quality and trust and positively affects attitudes toward local food advertisements. Local food consumers care about the freshness and safety of food and have a considerable interest in social and environmental value. They are interested in information about the production of local food. The more information available about local food, the more likely they are to consume such food. Therefore, it is important to develop a marketing communication strategy allowing consumers to easily access information related to local food. Local food marketing managers need to actively promote the healthrelated benefits of local food, to develop a program that allows consumers to know the information about the producers and the production process directly.

4.3. Suggestions for Future Research. Our study has some limitations. We chose a domestic grown fruit, melon, as an experimental stimulus to represent the local food; however, future research should examine the advertising message strategies in other product categories. Second, our participants were limited to Korean undergraduate students, and it is difficult to generalize our results. University students have relatively fewer opportunities to purchase vegetables and fruits than do housemakers. The actual buyer in the family may be someone else. It is more appropriate to conduct an experiment with a group that actually purchases local food. Third, as we controlled the exogenous variables for the experiment, the external validity decreased. We tried to make our experimental stimuli similar to the actual advertisement; however, we could not control the details of the advertising model in the producer's photo shot. Finally, one of the limitations of this study is that it did not reflect cultural differences. Wang et al. [61] examined the effect of the facial expressions of models in advertisements in both the United States and China. Both cultures showed more positive attitudes in positive expressions than neutral expressions. Furthermore, when the participants were exposed to advertisements with models of the same ethnicity, this positive effect increased. In South Korea, the concept image of a typical farmer is often an elderly male, as our experimental stimulus. However, the age, gender, and race of farmers can be diverse in other countries. Future research should examine the robustness of our findings.

\section{Data Availability}

The data used to support the findings of this study are restricted by the University of Seoul Institutional Review Board in order to protect participants' privacy. Data are available from the corresponding author upon request for researchers who meet the criteria for access to confidential data.

\section{Conflicts of Interest}

The authors declare that they have no conflicts of interest.

\section{References}

[1] R. Cowe and S. Willams, Who Are the Ethical Consumers?, The Co-operative Bank, London, UK, 2000.

[2] I. Szmigin and M. Carrigan, "Exploring the dimensions of ethical consumption," European Advances in Consumer Research, vol. 7, pp. 608-613, 2006.

[3] S. Maxwell and L. Comer, "The two components of a fair price: social and personal," Journal of Product \& Brand Management, vol. 19, no. 5, pp. 375-380, 2010.

[4] A. Crane and D. Matten, Business Ethics: Managing Corporate Citizenship and Sustainability in the Age of Globalization, Oxford University Press, Oxford, UK, 2016.

[5] M. Rabin, "The experimental study of social preferences," Social Research, vol. 73, no. 2, pp. 409-428, 2006.

[6] R. Harison, T. Newholm, and D. Shaw, The Ethical Consumer, Sage, Thousand Oaks, CA, USA, 2005.

[7] D. Clark and R. Unterberger, The Rough Guide to Shopping with a Conscience, Rough Guides Limited, London, UK, 2007.

[8] Embrain Trend Monitor, 2017, https://www.trendmonitor.co. $\mathrm{kr} / \mathrm{tmweb} / \mathrm{main} . \mathrm{do}$.

[9] C. Feldmann and U. Hamm, "Consumers' perceptions and preferences for local food: a review," Food Quality and Preference, vol. 40, pp. 152-164, 2015.

[10] L. Zepeda and D. Deal, "Organic and local food consumer behaviour: alphabet theory," International Journal of Consumer Studies, vol. 33, no. 6, pp. 697-705, 2009.

[11] H. L. Trobe, "Farmers' markets: consuming local rural produce," International Journal of Consumer Studies, vol. 25, no. 3, pp. 181-192, 2001.

[12] P. Megicks, J. Memery, and R. J. Angell, "Understanding local food shopping: unpacking the ethical dimension," Journal of Marketing Management, vol. 28, no. 3-4, pp. 264-289, 2012.

[13] T. Kogut and I. Ritov, "The "identified victim" effect: an identified group, or just a single individual?” Journal of Behavioral Decision Making, vol. 18, no. 3, pp. 157-167, 2005.

[14] J. Angelidis and N. A. Ibrahim, "The impact of emotional intelligence on the ethical judgment of managers," Journal of Business Ethics, vol. 99, no. S1, pp. 111-119, 2011. 
[15] A. C. Robinson, L. A. Downey, T. C. Ford, J. E. Lomas, and C. Stough, "Green teens: investigating the role of emotional intelligence in adolescent environmentalism," Personality and Individual Differences, vol. 138, pp. 225-230, 2019.

[16] M. C. Aguilar-Luzón, A. Calvo-Salguero, and J. M. Salinas, "Beliefs and environmental behavior: the moderating effect of emotional intelligence," Scandinavian Journal of Psychology, vol. 55, no. 6, pp. 619-629, 2014.

[17] H. Trobe, Local Food: Future Directions, Friends of the Earth, Slow food International, Bra, Italy, 2002.

[18] L. Zepeda and C. Nie, "What are the odds of being an organic or local food shopper? multivariate analysis of US food shopper lifestyle segments," Agriculture and Human Values, vol. 29, no. 4, pp. 467-480, 2012.

[19] C. A. Durham and C. A. Roheim, "Ranking of reasons for choosing local foods," Journal of Food Distribution Research, vol. 40, p. 198, 2009.

[20] Y. Onozaka, G. Nurse, and D. T. McFadden, "Local food consumers: how motivations and perceptions translate to buying behavior," Choices, vol. 25, pp. 1-6, 2010.

[21] Korea Customs and Trade Development Institution, http:// www.customs.go.kr.

[22] E. A. Simpson, S. E. Maylott, K. Leonard, R. J. Lazo, and K. V. Jakobsen, "Face detection in infants and adults: effects of orientation and color," Journal of Experimental Child Psychology, vol. 186, pp. 17-32, 2019.

[23] O. Droulers and S. Adil, "Could face presence in print ads influence memorization?" Journal of Applied Business Research (JABR), vol. 31, no. 4, pp. 1403-1408, 2015.

[24] S. Bakhshi, D. A. Shamma, and E. Gilbert, "Faces engage us: photos with faces attract more likes and comments on instagram," in Proceedings of the SIGCHI Conference on Human Factors in Computing Systems, pp. 965-974, Toronto, Cananda, 2014.

[25] G. Guido, M. Pichierri, G. Pino, and R. Nataraajan, "Effects of face images and face pareidolia on consumers' responses to print advertising," Journal of Advertising Research, vol. 59, no. 2, pp. 219-231, 2019.

[26] R. E. Petty, J. T. Cacioppo, and D. Schumann, "Central and peripheral routes to advertising effectiveness: the moderating role of involvement," Journal of Consumer Research, vol. 10, no. 2, pp. 135-146, 1983.

[27] D. J. MacInnis and B. J. Jaworski, "Information processing from advertisements: toward an integrative framework," Journal of Marketing, vol. 53, no. 4, pp. 1-23, 1989.

[28] U. Hess and P. Bourgeois, "You smile-I smile: emotion expression in social interaction," Biological Psychology, vol. 84, no. 3, pp. 514-520, 2010.

[29] U. Hess, S. Houde, and A. Fischer, "Do we mimic what we see or what we know?" Collective Emotions, pp. 94-107, 2014.

[30] P. Lewinski, M. L. Fransen, and E. S. H. Tan, "Predicting advertising effectiveness by facial expressions in response to amusing persuasive stimuli," Journal of Neuroscience, Psychology, and Economics, vol. 7, no. 1, pp. 1-14, 2014.

[31] G. Isabella and V. A. Vieira, "The effect of facial expression on emotional contagion and product evaluation in print advertising," RAUSP Management Journal, vol. 55, no. 3, 2020.

[32] R. Plutchik, Emotions and Life: Perspectives from Psychology, Biology, and Evolution, American Psychological Association, Washington, DC, USA, 2003.

[33] R. Neumann and F. Strack, "“Mood contagion": the automatic transfer of mood between persons," Journal of Personality and Social Psychology, vol. 79, no. 2, pp. 211-223, 2000.
[34] D. J. Howard and C. Gengler, "Emotional contagion effects on product attitudes: figure 1," Journal of Consumer Research, vol. 28, no. 2, pp. 189-201, 2001.

[35] S. T. Fiske and S. E. Taylor, Social Cognition, Mcgraw-Hill Book Company, New York, NY, USA, 1991.

[36] B. Z. Erdogan, "Celebrity endorsement: a literature review," Journal of Marketing Management, vol. 15, no. 4, pp. 291-314, 1999.

[37] R. Ohanian, "Construction and validation of a scale to measure celebrity endorsers' perceived expertise, trustworthiness, and attractiveness," Journal of Advertising, vol. 19, no. 3, pp. 39-52, 1990.

[38] D. A. Small and N. M. Verrochi, "The face of need: facial emotion expression on charity advertisements," Journal of Marketing Research, vol. 46, no. 6, pp. 777-787, 2009.

[39] P. Slovic, "If I look at the mass I will never act: psychic numbing and genocide," Judgement and Decision Making, vol. 2, no. 2, pp. 79-95, 2007.

[40] E.-J. Lee, D. H. Kim, and H. A. Choi, "Putting faces to sustainability marketing - an fMRI investigation of affective persuasion," Journal of Korean Marketing Association, vol. 32, no. 4, pp. 43-56, 2017.

[41] P. Salovey and J. D. Mayer, "Emotional intelligence," Imagination, Cognition and Personality, vol. 9, no. 3, pp. 185-211, 1990.

[42] M. Davies, L. Stankov, and R. D. Roberts, "Emotional intelligence: in search of an elusive construct," Journal of Personality and Social Psychology, vol. 75, no. 4, pp. 989-1015, 1998.

[43] C.-S. Wong and K. S. Law, "The effects of leader and follower emotional intelligence on performance and attitude," The Leadership Quarterly, vol. 13, no. 3, pp. 243-274, 2002.

[44] X. Huang, S. C. H. Chan, W. Lam, and X. Nan, "The joint effect of leader-member exchange and emotional intelligence on burnout and work performance in call centers in China," The International Journal of Human Resource Management, vol. 21, no. 7, pp. 1124-1144, 2010.

[45] J. Joseph, K. Berry, and S. P. Deshpande, "Impact of emotional intelligence and other factors on perception of ethical behavior of peers," Journal of Business Ethics, vol. 89, no. 4, pp. 539-546, 2009.

[46] W. Fu, "The impact of emotional intelligence, organizational commitment, and job satisfaction on ethical behavior of Chinese employees," Journal of Business Ethics, vol. 122, no. 1, pp. 137-144, 2014.

[47] R. M. M. I. Chowdhury, "Emotional intelligence and consumer ethics: the mediating role of personal moral philosophies," Journal of Business Ethics, vol. 142, no. 3, pp. 527-548, 2017.

[48] J. D. Mayer, R. D. Roberts, and S. G. Barsade, "Human abilities: emotional intelligence," Annual Review of Psychology, vol. 59, no. 1, pp. 507-536, 2008.

[49] J. D. Mayer and P. Salovey, "What is emotional intelligence?" in Emotional Development and Emotional Intelligence: Implications for Educators, P. Salovey and D. Sluyter, Eds., pp. 3-31, Basic Books, New York, NY, USA, 1997.

[50] N. S. Schutte, J. M. Malouff, C. Bobik et al., "Emotional intelligence and interpersonal relations," The Journal of Social Psychology, vol. 141, no. 4, pp. 523-536, 2001.

[51] J. Fitness and M. Curtis, "Emotional intelligence and the trait meta-mood scale: relationships with empathy, attributional complexity, self-control, and responses to interpersonal conflict," E-journal of Applied Psychology, vol. 1, no. 1, pp. 50-62, 2005. 
[52] G. A. Verhaert and D. Van den Poel, "Empathy as added value in predicting donation behavior," Journal of Business Research, vol. 64, no. 12, pp. 1288-1295, 2011.

[53] FTA strong country, Korea, each FTA, http://www.fta.go.kr.

[54] C. E. Izard, The Psychology of Emotions, Springer Science \& Business Media, Berlin, Germany, 1991.

[55] R. W. Olshavsky and J. A. Miller, "Consumer expectations, product performance, and perceived product quality," Journal of Marketing Research, vol. 9, no. 1, pp. 19-21, 1972.

[56] S. Ganesan and R. Hess, "Dimensions and levels of trust: implications for commitment to a relationship," Marketing Letters, vol. 8, no. 4, pp. 439-448, 1997.

[57] P. M. Homer, "The mediating role of attitude toward the ad: some additional evidence," Journal of Marketing Research, vol. 27, no. 1, pp. 78-86, 1990.

[58] P. H. Bloch and M. L. Richins, "A theoretical model for the study of product importance perceptions," Journal of Marketing, vol. 47, no. 3, pp. 69-81, 1983.

[59] J. L. Zaichkowsky, "Measuring the involvement construct," Journal of Consumer Research, vol. 12, no. 3, pp. 341-352, 1985.

[60] P. Fernández-Berrocal, N. Extremera, P. N. Lopes, and D. Ruiz-Aranda, "When to cooperate and when to compete: emotional intelligence in interpersonal decision-making," Journal of Research in Personality, vol. 49, pp. 21-24, 2014.

[61] Q. Wang, M. Wedel, and X. Liu, "How facial cues of models affect attention to websites in Asian and American cultures," Robert H. Smith School Research Paper No. RHS, University of Maryland, College Park, MA, USA, Article ID 2539253, 2014. 